\title{
Evaluation of flavonoids and enterolactone in overnight urine as intake biomarkers of fruits, vegetables and beverages in the Inter99 cohort study using the method of triads
}

\author{
Kirstine S. Krogholm ${ }^{1 *}$, Anette Bysted ${ }^{2}$, Anne Lise Brantsæter ${ }^{3}$, Jette Jakobsen ${ }^{2}$, Salka E. Rasmussen ${ }^{4}$, \\ Lis Kristoffersen ${ }^{5}$ and Ulla Toft ${ }^{5}$ \\ ${ }^{1}$ Department of Toxicology and Risk Assessment, National Food Institute, Technical University of Denmark, Mørkhøj Bygade \\ 19, DK-2860 Søborg, Denmark \\ ${ }^{2}$ Department of Food Chemistry, National Food Institute, Technical University of Denmark, Mørkhøj Bygade 19, \\ DK-2860 Søborg, Denmark \\ ${ }^{3}$ Department of Exposure and Risk Assessment, Norwegian Institute of Public Health, PO Box 4404, Nydalen, \\ Oslo NO-0403, Norway \\ ${ }^{4}$ Diabetes Research Unit, ADME Department, Novo Nordisk A/S, Novo Nordisk Park, 2760 Måløv, Denmark \\ ${ }^{5}$ Research Centre for Prevention and Health, Glostrup University Hospital, DK-2600 Glostrup, Denmark
}

(Submitted 3 August 2011 - Final revision received 14 December 2011 - Accepted 6 January 2012 - First published online 27 March 2012)

\begin{abstract}
Since collection of $24 \mathrm{~h}$ urine samples is very time consuming and difficult to obtain, epidemiological studies typically only obtain spot urine samples. The aim of the present study was to evaluate whether flavonoids and enterolactone in overnight urine could substitute flavonoids and enterolactone in $24 \mathrm{~h}$ urine as an alternative and more feasible biomarker of fruit, vegetable and beverage intake. A total of 191 individuals in the Inter99 cohort in Denmark completed the validation study. Concentrations of nine urinary flavonoid aglycones (quercetin, isorhamnetin, tamarixetin, kaempferol, hesperetin, naringenin, eriodictyol, phloretin and apigenin) and enterolactone were determined in overnight and $24 \mathrm{~h}$ urine samples, and their validity as biomarkers of fruit, vegetable and beverage intake was evaluated in relation to two independent reference methods (Inter99 FFQ data and plasma carotenoids) by using the method of triads. The intakes of fruit, juice, vegetables and tea reported in the FFQ were reflected by the flavonoid biomarker both in overnight and $24 \mathrm{~h}$ urine samples. Validity coefficients for the flavonoid biomarker in overnight urine ranged from 0.39 to $0 \cdot 49$, while the corresponding validity coefficients for the biomarker in $24 \mathrm{~h}$ urine ranged from 0.43 to 0.66 . Although the validity coefficients were lower for overnight urine than for the $24 \mathrm{~h}$ urine flavonoid biomarker, they were still of acceptable magnitude. In conclusion, the results indicate that flavonoids and enterolactone in overnight urine samples may be used as a more feasible biomarker than $24 \mathrm{~h}$ urine for the assessment and validation of fruit, juice, vegetable and tea intakes in epidemiological studies.
\end{abstract}

Key words: Validation: FFQ: Urinary flavonoids: Enterolactone: 24 h urine: Overnight urine: Plasma carotenoids

Precise ranking of fruit and vegetable intake is important in nutritional epidemiology in order to elucidate the effects of fruit and vegetables on health and disease. The FFQ has been the dominant instrument in nutritional epidemiology for more than 30 years ${ }^{(1)}$. However, every new or adjusted FFQ has to be validated to get an expression of the degree to which it is an accurate measure in the target population. Dietary biomarkers represent an objective alternative to the traditional food registration methods ${ }^{(2,3)}$. However, biomarkers that directly reflect the intake of a food group are scarce, and there is a great need of a larger variety of dietary biomarkers to be developed. Previously, the plasma concentration of carotenoids $^{(4-13)}$ and the $24 \mathrm{~h}$ urinary excretion of flavonoids ${ }^{(9,14,15)}$ have been used as independent reference methods in the validation of self-reported intake of fruits and vegetables. A few studies have validated selfreported fruit and vegetable intakes using plasma carotenoids and the $24 \mathrm{~h}$ urinary excretion of flavonoids in combination by using the method of triads ${ }^{(16,17)}$. Collection of $24 \mathrm{~h}$ urine samples impose a larger burden on participants, and a biomarker measured in overnight or spot urine samples would thus be very valuable as an independent measure or for the validation of dietary instruments. Previous studies ${ }^{(18-20)}$ showed that the excretion of flavonoids, lignans and phenolic

Abbreviations: LC, liquid chromatography; P5, 5th percentile; P95, 95th percentile; VC, validity coefficient. 
acids in overnight urine can be used as biomarkers of intake for polyphenol-rich foods. The aim of the present study was to evaluate whether the urinary recovery of flavonoids and enterolactone in an overnight urine sample could substitute the $24 \mathrm{~h}$ urinary recovery of flavonoid aglycones and enterolactone as an alternative and more feasible biomarker of fruit, vegetable and beverage intake.

\section{Materials and methods \\ Subjects and study design}

The overall aim of the Inter99 study was to decrease the incidence of IHD. An age- and sex-stratified random sample of 13016 individuals born from 1939 to 1940 and living in the south-western part of Copenhagen was drawn from the study population that comprised 61301 individuals. Of these, eighty-two individuals were non-eligible, as they had died or could not be traced. The remaining 12934 subjects were invited for a health-screening programme at the Research Centre for Prevention and Health. A total of 6906 $(53.4 \%)$ turned up for the investigation. Of these, 122 were excluded because of alcoholism, drug abuse or linguistic barriers. Individuals at high risk of developing IHD were reinvited after 1 and 3 years, and completed a 198-item FFQ at each time point. Individuals were categorised as high-risk individuals if they had either an absolute risk in the upper quintile of the distribution stratified according to sex and age or at least one of the following isolated risk factors: systolic blood pressure $\geq 160 \mathrm{mmHg}$ and/or in antihypertensive treatment; total cholesterol $\geq 7.5 \mathrm{mmol} / \mathrm{l} ; \quad \mathrm{BMI} \geq 30 \mathrm{~kg} / \mathrm{m}^{2}$; diabetes or glucose intolerance ${ }^{(21)}$; or were daily smokers. The Inter99 study has been described in detail elsewhere ${ }^{(22)}$.

\section{The validation study}

Individuals attending the 3-year follow-up visit between 10 June 2002 and 16 February 2004 were personally and sequentially invited to participate in the validation study that, in addition to answering the FFQ, included: a 28-d diet history interview; collection of a $24 \mathrm{~h}$ and an overnight urine sample; and donating a blood sample. The 28-d diet history data were not included in the present study since the aim of the present study was to validate the flavonoid biomarker using two independent reference methods: plasma carotenoids and the FFQ. Participants included in the validation study did not differ from other participants at 3-years followup with respect to age, sex, physical activity, dietary habits, smoking, employment, diabetes, BMI and cholesterol (data not shown). A total of 284 individuals accepted participation in the validation study, of which seventeen did not turn up for the interview and two participants did not complete the FFQ, leaving 265 participants.

\section{The 198-item FFQ}

The FFQ applied on the Inter99 cohort has been described elsewhere $^{(10)}$. In short, the FFQ is a semi-quantitative questionnaire consisting of 198 food items and beverages. Participants were asked to report their average intake of different foods and beverages during the last month and included eight questions concerning fruit intake, eight questions on vegetable intake, one question on fruit juice intake, one question on vegetable juice intake and one question about tea and coffee intake. The questionnaire consisted of sixteen sections: number of meals; breakfast; bread and fat spread on bread; cheese, meat and fish, etc. laid on bread; hot meals; accompaniments to hot meals; sauces; fats for cooking; fast food; vegetables; salad dressing; fruits; snacks; candy/ice cream/chocolate; cookies; beverages. The food consumption quantity was obtained by multiplying the frequency of consumption of each unit of food by standard portion sizes. Daily food consumption was translated into energy and nutrient intakes using the Danish Food Composition Databank, version $6^{(23)}$ and the software program FoodCalc version $1.3^{(24)}$.

\section{Collection and preparation of urine samples}

Participants collected urine for $24 \mathrm{~h}$ within 2 weeks after completing the FFQ. The purpose of the urine collection was unknown to the participants, but the time for the collection was agreed upon before the start of the study. At the day for urine collection, the first morning urine void was discarded and all subsequent voids until 24.00 hours on the same day were collected. The overnight urine, defined as all urine voids from 24.00 hours including the first morning void, was collected separately. The $24 \mathrm{~h}$ urine sample constituted the sum of the two separate collections. All urine samples were kept cool and dark during collection. The subjects brought the urine collections to the study site immediately after ending the collection, where they were put in a fridge until weighed and adjusted to $\mathrm{pH} 3-4$ with $1 \mathrm{M}-\mathrm{HCl}$ and stored at $-20^{\circ} \mathrm{C}$ for a maximum of 1 month and afterwards at $-80^{\circ} \mathrm{C}$ until analysis. Any urine collection which showed a para-aminobenzoic acid recovery below the limit classified as incomplete was excluded. For the HPLC method performed in the present study, the limit for completeness of $24 \mathrm{~h}$ urine has previously been assessed to $78 \%$ recovery ${ }^{(25)}$.

\section{Determination of flavonoid aglycones and enterolactone in the urine}

The concentrations of nine urinary flavonoid aglycones (quercetin, isorhamnetin, tamarixetin, kaempferol, hesperetin, naringenin, eriodictyol, phloretin and apigenin) and enterolactone were determined in $24 \mathrm{~h}$ urine and overnight urine samples by liquid chromatography (LC)-MS. Urine samples $(2 \mathrm{ml})$ were subjected to enzymatic hydrolysis and solidphase extraction before LC-MS analysis, as described in detail previously ${ }^{(26,27)}$. The flavonoid concentrations in the urine samples were determined as single determinations based on calibration curves generated by spiked blank urine samples ${ }^{(26)}$. In addition, supplementary calibration samples were included at the beginning, during and at the end of each series of samples, and a final adjustment was performed based on the level of the internal standards in each sample. 
Before and after each series of samples, the performance of the entire LC-MS assay was controlled by injections of aliquots containing all of the employed flavonoid standards, including the internal standards. There was no access to the applied LC-MS instrument when the urine samples with low internal standards were identified during the subsequent data processing, and consequently these samples had to be excluded instead of being re-analysed.

\section{Collection and determination of carotenoids in the plasma}

Fasting blood samples $(<8 \mathrm{~h})$ were drawn at the day of completing the FFQ, and it was unknown to the participants that the concentration of six carotenoids (lutein, zeaxanthin, $\beta$-cryptoxanthin, $\alpha$-carotene, $\beta$-carotene and lycopene) would be analysed in the blood samples as a biomarker of fruit and vegetable intake. Plasma was treated with ethanol to precipitate proteins, and the carotenoids were extracted and determined, as described in detail previously ${ }^{(10)}$.

\section{Statistical analysis}

The concentration of biomarkers and intake of fruit, vegetables and beverages did not have a normal distribution, so non-parametric tests were used in the statistical analysis of the data. We used linear regression to examine whether sex influenced the associations between the biomarkers and intake estimates, with the cross-product of sex and the biomarker as an interaction term. In order to fulfil model assumptions, square root transformation was applied to the variables. The Mann-Whitney $U$ test was used to test differences between the groups and Spearman's correlation coefficients $\left(r_{\mathrm{s}}\right)$ were used for the calculation of the correlations between the biomarkers and between the intake of various food groups and the reference measures. An intraclass correlation coefficient was calculated for evaluating the agreement between quintiles of the flavonoid biomarker by $24 \mathrm{~h}$ urine and overnight urine.

Triangular validity coefficients (VC) were calculated for the FFQ and each of the biomarkers by the following equation: $\mathrm{VC}=\sqrt{r_{1} \times r_{2} / r_{3}}$, where $r_{1}$ is the correlation between the FFQ and biomarker 1 (flavonoid biomarker), $r_{2}$ is the correlation between the FFQ and biomarker 2 (carotenoid biomarker) and $r_{3}$ is the correlation between the two biomarkers ${ }^{(28,29)}$. We used maximum-likelihood estimation and bootstrap sampling with the statistical program $\mathrm{R}^{(30)}$ to estimate $\mathrm{VC}$ and $95 \% \mathrm{CI}$ for these. Use of maximum-likelihood estimation eliminates the problems related to possible negative correlations or calculating VC larger than one, as explained elsewhere ${ }^{(29)}$.

All other analyses were performed with SPSS, version 14.0 (SPSS, Inc.). $P$ values $<0.05$ (two-tailed) were considered as statistically significant.

\section{Results}

\section{Subjects}

A total of 264 individuals participated in the validation study. The urine collections were incomplete for thirty-seven participants according to the para-aminobenzoic acid method. Furthermore, thirty-three participants were excluded due to low internal standard values identified during data processing and the lack of opportunity for quality control by re-analysis. Also, five participants were excluded because of incomplete dietary data, leaving 191 participants for the present study.

There were no differences in age, BMI, or any flavonoids or enterolactone excreted in $24 \mathrm{~h}$ urine between the male and female participants, while enterolactone and kaempferol in overnight urine were higher for women than for men (Table 1). Furthermore, we found no significant interactions with sex when examining the correlations between the intakes and the biomarkers, and consequently we performed all further analyses without stratifying by sex.

\section{Biomarkers}

The median excretion of the sum of flavonoid aglycones and enterolactone in $24 \mathrm{~h}$ urine was 864 (5th percentile (P5) 258, 95th percentile (P95) 4659) $\mu \mathrm{g} / \mathrm{g}$ creatinine. The quantitative largest amounts of flavonoids in $24 \mathrm{~h}$ urine were the citrus flavonoids naringenin and hesperetin (Table 2). The median $24 \mathrm{~h}$ urinary excretion of enterolactone was 233 (P5 13, P95 1306) $\mu \mathrm{g} / \mathrm{mg}$ creatinine. In overnight urine, the excretion of the sum of flavonoids and enterolactone was 672 (P5 184, P95 5433) $\mu \mathrm{g} / \mathrm{g}$ creatinine, and also here the citrus flavonoids were the quantitative largest group of flavonoids excreted. For the quantitatively major flavonoids, the excretion was higher in $24 \mathrm{~h}$ urine than in overnight urine. The flavonoid and enterolactone excretion in overnight urine strongly correlated with flavonoid and enterolactone excretion in the $24 \mathrm{~h}$ urine samples, and were $>0.5$ for all but phloretin and apigenin (Table 2).

Ranking of the flavonoid biomarker (flavonoids + enterolactone) in $24 \mathrm{~h}$ urine and overnight urine into quartiles resulted in weighted $\kappa$ (intraclass correlation coefficient) of 0.71 (95\% CI 0.63, 0.78). Furthermore, $84 \%$ of the participants were ranked into the same or adjacent quintiles by overnight spot urine and $24 \mathrm{~h}$ urine and the degree of misclassification (opposing quintiles) was low (1.3\%).

The median concentration of the sum of six carotenoids in the plasma was 0.9 (P5 0.4, P95 2.2) $\mathrm{mmol} / \mathrm{l}$. The largest amounts of carotenoids were as follows: lycopene 0.3 (P5 $0 \cdot 1, \quad$ P95 0.54$) \mu \mathrm{mol} / 1, \quad \beta$-carotene $0.14 \quad$ (P5 0.03, P95 $0.54) \mu \mathrm{mol} / \mathrm{l}$, phytoene 0.11 (P5 0.04, P95 0.33 ) $\mu \mathrm{mol} / \mathrm{l}$ and lutein $0 \cdot 11$ (P5 0.05, P95 0.25) $\mu \mathrm{mol} / 1$ (data not shown).

\section{Correlations between the biomarkers and the intake of fruits, vegetables and beverages}

The FFQ-estimated fruit and fruit juice intake and the vegetable intake were in general more strongly correlated with the carotenoid concentrations than with the urinary flavonoid aglycones and enterolactone in the present study. On the contrary, the intake of tea and wine was more strongly correlated with the excretion of flavonoid aglycones and enterolactone in the urine (Table 3). The strongest correlations were found between all fruits, juices and vegetables except potatoes and 
Table 1. Age, BMI, urinary excretion of flavonoids and enterolactone in $24 \mathrm{~h}$ urine and overnight urine stratified by sex* (Medians, and 5th (P5) and 95th (P95) percentiles)

\begin{tabular}{|c|c|c|c|c|c|}
\hline & \multicolumn{2}{|c|}{ Male $(n 84)$} & \multicolumn{2}{|c|}{ Female ( $n$ 107) } & \multirow[b]{2}{*}{$P$} \\
\hline & Median & P5, P95 & Median & P5, P95 & \\
\hline Age (years) & $48 \cdot 6$ & $38 \cdot 3,63 \cdot 1$ & 48.5 & $38 \cdot 3,63 \cdot 2$ & 0.055 \\
\hline BMI $\left(\mathrm{kg} / \mathrm{m}^{2}\right)$ & 28.0 & $22 \cdot 3,37 \cdot 8$ & $26 \cdot 2$ & $20 \cdot 4,39 \cdot 3$ & 0.800 \\
\hline \multicolumn{6}{|c|}{ Hesperetin ( $\mu \mathrm{g} / \mathrm{g}$ creatinine) } \\
\hline $24 \mathrm{~h}$ urine & 47.4 & 0,2647 & $36 \cdot 5$ & 0,2011 & 0.468 \\
\hline Overnight urine & $42 \cdot 1$ & 0,3044 & $32 \cdot 1$ & 0,1431 & 0.457 \\
\hline \multicolumn{6}{|c|}{ Naringenin ( $\mu \mathrm{g} / \mathrm{g}$ creatinine) } \\
\hline $24 \mathrm{~h}$ urine & 166 & $30 \cdot 1,1607$ & 205 & $36 \cdot 7,1283$ & 0.107 \\
\hline Overnight urine & 104 & $19 \cdot 9,2099$ & 143 & $28 \cdot 9,1768$ & 0.233 \\
\hline \multicolumn{6}{|c|}{ Eriodictyol ( $\mu \mathrm{g} / \mathrm{g}$ creatinine) } \\
\hline $24 \mathrm{~h}$ urine & $17 \cdot 6$ & $8 \cdot 3,91 \cdot 9$ & $22 \cdot 2$ & $3 \cdot 4,281$ & 0.559 \\
\hline Overnight urine & 0.87 & 0,123 & 0 & 0,129 & 0.210 \\
\hline \multicolumn{6}{|c|}{ Phloretin ( $\mu \mathrm{g} / \mathrm{g}$ creatinine) } \\
\hline $24 \mathrm{~h}$ urine & $29 \cdot 7$ & 0,120 & $32 \cdot 6$ & 0,154 & 0.187 \\
\hline Overnight urine & 0 & 0,177 & 0 & $0,66 \cdot 1$ & 0.287 \\
\hline \multicolumn{6}{|c|}{ Quercetin ( $\mu \mathrm{g} / \mathrm{g}$ creatinine) } \\
\hline $24 \mathrm{~h}$ urine & $17 \cdot 6$ & $3 \cdot 4,97 \cdot 2$ & $20 \cdot 6$ & $5 \cdot 0,67 \cdot 8$ & 0.240 \\
\hline Overnight urine & $21 \cdot 6$ & $0,93.7$ & 28.9 & $0,74.8$ & 0.080 \\
\hline \multicolumn{6}{|c|}{ Kaempferol ( $\mu \mathrm{g} / \mathrm{g}$ creatinine) } \\
\hline $24 \mathrm{~h}$ urine & 7.55 & $0,78 \cdot 8$ & $10 \cdot 8$ & $0,71 \cdot 7$ & 0.863 \\
\hline Overnight urine & $30 \cdot 2$ & $0,80 \cdot 9$ & $37 \cdot 1$ & $0,106 \cdot 8$ & 0.034 \\
\hline \multicolumn{6}{|c|}{ Isorhamnetin ( $\mu \mathrm{g} / \mathrm{g}$ creatinine) } \\
\hline $24 \mathrm{~h}$ urine & 3.28 & $0,28 \cdot 4$ & $4 \cdot 18$ & $0,33.2$ & 0.128 \\
\hline Overnight urine & 19.4 & $0,64 \cdot 0$ & 22.5 & $0,65.5$ & 0.578 \\
\hline \multicolumn{6}{|c|}{ Tamarixetin ( $\mu \mathrm{g} / \mathrm{g}$ creatinine) } \\
\hline $24 \mathrm{~h}$ urine & $4 \cdot 30$ & $0,24 \cdot 3$ & $6 \cdot 19$ & $0,24 \cdot 0$ & 0.426 \\
\hline Overnight urine & $22 \cdot 7$ & $0,62 \cdot 2$ & $24 \cdot 7$ & $0,71 \cdot 3$ & 0.691 \\
\hline \multicolumn{6}{|c|}{ Apigenin ( $\mu \mathrm{g} / \mathrm{g}$ creatinine) } \\
\hline $24 \mathrm{~h}$ urine & $10 \cdot 2$ & 0,276 & $12 \cdot 6$ & 0,287 & 0.601 \\
\hline Overnight urine & $17 \cdot 4$ & $0,48 \cdot 0$ & $17 \cdot 3$ & $0,66 \cdot 5$ & 0.650 \\
\hline \multicolumn{6}{|c|}{ Enterolactone ( $\mu \mathrm{g} / \mathrm{g}$ creatinine) } \\
\hline $24 \mathrm{~h}$ urine & 191 & $6 \cdot 76,880$ & 261 & $37 \cdot 8,1514$ & 0.060 \\
\hline Overnight urine & 173 & 0,879 & 241 & $40 \cdot 8,2176$ & 0.007 \\
\hline \multicolumn{6}{|c|}{ Sum of all flavonoid aglycones and enterolactone ( $\mu \mathrm{g} / \mathrm{g}$ creatinine) } \\
\hline $24 \mathrm{~h}$ urine & 778 & 257,6403 & 907 & 277,4297 & 0.258 \\
\hline Overnight urine & 567 & 178,5932 & 712 & 188,5013 & 0.136 \\
\hline
\end{tabular}

* Mann-Whitney $U$ test.

$\alpha$-carotene $\left(r_{\mathrm{s}}=0.44\right)$, and between $\beta$-cryptoxanthin and citrus fruits and juices $\left(r_{\mathrm{s}}=0.43\right)$ and $\alpha$-carotene and all vegetables $\left(r_{\mathrm{s}}=0.43\right)$. The strongest correlation between the flavonoids in the urine and food intake was seen for citrus fruits and juices and citrus flavonoids $\left(r_{\mathrm{s}}=0.38\right)$, and for tea intake and kaempferol $\left(r_{\mathrm{s}}=0 \cdot 37\right)$. No significant correlations were seen between biomarkers and coffee consumption. Potato intake showed significant negative correlation with lutein and non-significant negative correlation with the sum of all the nine flavonoids and enterolactone (data not shown).

Statistically significant correlations between the urine and plasma biomarkers were found between plasma $\beta$-cryptoxanthin

Table 2. Flavonoid aglycones and enterolactone excretion and correlations between $24 \mathrm{~h}$ urine and overnight urine in the validation study ( $n$ 191) within the Inter99 study

(Medians, and 5th (P5) and 95th (P95) percentiles; correlation coefficients ( $r$ ) and $95 \%$ confidence intervals)

\begin{tabular}{|c|c|c|c|c|c|c|}
\hline \multirow[b]{2}{*}{ Flavonoid aglycone or enterolactone ( $\mu \mathrm{g} / \mathrm{g}$ creatinine) } & \multicolumn{2}{|c|}{$24 \mathrm{~h}$ urine } & \multicolumn{2}{|c|}{ Overnight urine } & \multicolumn{2}{|c|}{ Spearman } \\
\hline & Median & P5, P95 & Median & P5, P95 & $r$ & $95 \% \mathrm{Cl}$ \\
\hline Hesperetin & $40 \cdot 0$ & 0,2443 & $33 \cdot 8$ & 0,1542 & 0.69 & $0.61,0.76$ \\
\hline Naringenin & 192 & $33 \cdot 6,1563$ & 118 & $23 \cdot 6,1914$ & 0.72 & $0.67,0.80$ \\
\hline Eriodictyol & 20.3 & $4.94,198$ & 0.0 & 0,143 & 0.52 & $0.40,0.61$ \\
\hline Phloretin & $31 \cdot 2$ & 0,153 & 0.0 & $0,99.9$ & 0.28 & $0.14,0.40$ \\
\hline Quercetin & 19.5 & $4 \cdot 19,76 \cdot 1$ & $24 \cdot 1$ & $0,92 \cdot 1$ & 0.64 & $0.55,0.72$ \\
\hline Kaempferol & 9.47 & $0,80.3$ & $34 \cdot 2$ & 0,104 & 0.62 & $0.53,0.70$ \\
\hline Isorhamnetin & $3 \cdot 78$ & $0,33.5$ & $20 \cdot 8$ & $0,65.5$ & 0.59 & $0.49,0.67$ \\
\hline Tamarixetin & 4.99 & $0,25 \cdot 5$ & $24 \cdot 0$ & $0,72 \cdot 3$ & 0.58 & $0.48,0.67$ \\
\hline Apigenin & $12 \cdot 2$ & 0,289 & $17 \cdot 3$ & $0,58.5$ & 0.08 & $-0.07,0.22$ \\
\hline Enterolactone & 233 & $12 \cdot 7,1306$ & 218 & $13 \cdot 3,1601$ & 0.89 & $0.87,0.92$ \\
\hline Sum of all flavonoids + enterolactone & 864 & 258,4659 & 672 & 184,5433 & 0.76 & $0.69,0.81$ \\
\hline
\end{tabular}


Table 3. Bivariate correlations between the intake of fruits, vegetables and beverages determined by the FFQ and the biomarkers (BM) in $24 \mathrm{~h}$ urine, overnight urine and plasma ( $n$ 191)

\begin{tabular}{|c|c|c|c|c|c|c|}
\hline Fruits, vegetables and beverages & $\begin{array}{l}\text { Flavonoids and enterolactone } \\
\text { (24 h urine) }\end{array}$ & $\begin{array}{l}\text { Correlation } \\
\text { FFQ-BM }\end{array}$ & $\begin{array}{l}\text { Flavonoids and enterolactone } \\
\text { (overnight urine) }\end{array}$ & $\begin{array}{l}\text { Correlation } \\
\text { FFQ-BM }\end{array}$ & $\begin{array}{l}\text { Carotenoids } \\
\text { (plasma) }\end{array}$ & $\begin{array}{c}\text { Correlation } \\
\text { FFQ-BM }\end{array}$ \\
\hline Apples & Phloretin & $0 \cdot 19^{\star \star}$ & Phloretin & $0.12^{\mathrm{NS}}$ & $\alpha$-Carotene & $0.43^{* \star}$ \\
\hline Tomatoes & Flav + ent & $0 \cdot 17^{\star}$ & Flav + ent & $0.13^{\mathrm{NS}}$ & $\begin{array}{l}\text { Phytoen } \\
\text { Lycopene }\end{array}$ & $\begin{array}{l}0.24^{* *} \\
0.12^{\mathrm{NS}}\end{array}$ \\
\hline \multirow[t]{3}{*}{ Citrus fruits and juices } & Naringenin & $0.37^{\star \star}$ & Naringenin & $0.18^{\star}$ & $\beta$-Cryptoxanthin & $0.43^{\star \star}$ \\
\hline & Hesperetin & $0.33^{\star \star}$ & Hesperetin & $0.29^{\star \star}$ & Zeaxanthin & $0 \cdot 28^{\star \star}$ \\
\hline & Citrus flavonoids & $0.38^{* *}$ & Citrus flavonoids & $0.23^{\star *}$ & & \\
\hline \multirow[t]{3}{*}{ All fruit juices } & Naringenin & $0.30^{\star \star}$ & Naringenin & $0.21^{\star \star}$ & $\beta$-Cryptoxanthin & $0.33^{\star \star}$ \\
\hline & Hesperetin & $0.27^{\star *}$ & Hesperetin & $0 \cdot 24^{\star \star}$ & Zeaxanthin & $0.30^{* *}$ \\
\hline & Citrus flavonoids & $0.32^{\star \star}$ & Citrus flavonoids & $0 \cdot 24^{\star *}$ & & \\
\hline \multirow[t]{3}{*}{ All fruits, berries, juices and jams } & Phloretin & $0.03^{\mathrm{NS}}$ & Phloretin & $0 \cdot 18^{\star}$ & Lutein, $\alpha$ - and $\beta$-carotene & $0.27^{\star \star}$ \\
\hline & Citrus flavonoids & $0.14^{* *}$ & Citrus flavonoids & $0 \cdot 10^{\mathrm{NS}}$ & $\beta$-Cryptoxanthin & $0 \cdot 17^{*}$ \\
\hline & Flav + ent & $0 \cdot 19^{\star \star}$ & Flav + ent & $0 \cdot 13^{\mathrm{NS}}$ & All carotenoids & $0.20^{\star}$ \\
\hline \multirow[t]{3}{*}{ Legumes } & Quercetin & $0.12^{\mathrm{NS}}$ & Quercetin & $0.06^{\mathrm{NS}}$ & Lutein & $0.37^{\star \star}$ \\
\hline & Ent & $0.22^{\star \star}$ & Ent & $0.19^{\star \star}$ & Lutein, $\alpha$ - and $\beta$-carotene & $0.39^{\star \star}$ \\
\hline & Flav + ent & $0.14^{\mathrm{NS}}$ & Flav + ent & $0.17^{\star}$ & & \\
\hline Potatoes & Flav + ent & $-0.00^{\mathrm{NS}}$ & Flav + ent & $0.02^{\mathrm{NS}}$ & All carotenoids & $\begin{array}{l}-0.14^{\star} \\
-0.19^{* \star}\end{array}$ \\
\hline \multirow[t]{2}{*}{ Carrots } & Flav + ent & $0 \cdot 19^{\star *}$ & Flav + ent & $0 \cdot 15^{\star}$ & $\alpha$-Carotene & $0.41^{\star *}$ \\
\hline & Ent & $0.21^{\star *}$ & Ent & $0.19^{\star \star}$ & $\beta$-Carotene & $0.36^{\star \star}$ \\
\hline \multirow[t]{2}{*}{ Cruciferous vegetables } & Ent & $0 \cdot 16^{\star}$ & Ent & $0.13^{\mathrm{NS}}$ & $\alpha$-Carotene & $0.38^{\star \star}$ \\
\hline & Flavonols & $0.08^{\mathrm{NS}}$ & Flavonols & $0.16^{\star}$ & Lutein & $0.36^{* *}$ \\
\hline \multirow[t]{2}{*}{ All vegetables including potatoes } & Ent & $0.26^{\star \star}$ & Ent & $0.21^{* *}$ & $\alpha$-Carotene & $0.43^{\star *}$ \\
\hline & Flav + ent & $0.33^{\star \star}$ & Flav + ent & $0.18^{*}$ & All carotenoids & $0.27^{\star \star}$ \\
\hline \multirow[t]{2}{*}{ All vegetables except potatoes } & Ent & $0.28^{\star \star}$ & Ent & $0.24^{\star \star}$ & $\alpha$-Carotene & $0.43^{\star *}$ \\
\hline & Flav + ent & $0.25^{\star *}$ & Flav + ent & $0 \cdot 15^{\star}$ & All carotenoids & $0.34^{\star *}$ \\
\hline \multirow[t]{5}{*}{ All fruits, juices and vegetables including potatoes } & Flav + ent & $0.33^{\star \star}$ & Flav + ent & $0.19^{\star \star}$ & $\alpha$-Carotene & $0.44^{\star \star}$ \\
\hline & Ent & $0.32^{\star \star}$ & Ent & $0.26^{\star \star}$ & All carotenoids & $0.30^{\star \star}$ \\
\hline & Naringenin & $0 \cdot 27^{\star *}$ & Naringenin & $0 \cdot 10^{\mathrm{NS}}$ & Lutein, $\alpha$ - and $\beta$-carotene & $0.42^{\star *}$ \\
\hline & Hesperetin & $0.20^{* \star}$ & Hesperetin & $0.19^{* *}$ & & \\
\hline & Citrus flavonoids & $0.27^{\star \star}$ & Citrus flavonoids & $0.14^{\mathrm{NS}}$ & & \\
\hline \multirow[t]{3}{*}{ All fruits, juices and vegetables except potatoes } & Flav + ent & $0 \cdot 22^{\star \star}$ & Flav + ent & $0 \cdot 14^{\mathrm{NS}}$ & $\alpha$-Carotene & $0.36^{\star \star}$ \\
\hline & Ent & $0.23^{\star \star}$ & Ent & $0.20^{* \star}$ & All carotenoids & $0.26^{\star \star}$ \\
\hline & Naringenin & $0.16^{\star}$ & Naringenin & $0.09^{\mathrm{NS}}$ & Lutein, $\alpha$ - and $\beta$-carotene & $0.34^{\star \star}$ \\
\hline Tea & Kaempferol & $0.37^{\star *}$ & Kaempferol & $0.16^{\star}$ & Lutein, $\alpha$ - and $\beta$-carotene & $0 \cdot 17^{\star}$ \\
\hline Coffee & Kaempferol & $-0 \cdot 17^{\star}$ & Kaempferol & $-0.05^{\mathrm{NS}}$ & & \\
\hline Red wine & Quercetin & $0.17^{\star}$ & Quercetin & $0.04^{\mathrm{NS}}$ & Phytoen & $0.16^{*}$ \\
\hline White wine & Flav + ent & $0.13^{\mathrm{NS}}$ & Flav + ent & $0 \cdot 17^{\star}$ & & \\
\hline
\end{tabular}

Flav + ent, all nine flavonoids and enterolactone; ent, enterolactone; citrus flavonoids, sum of hesperetin, naringenin and eriodictyol; flavonols, sum of quercetin, kaempferol, isorhamnetin and tamarixetin.

Correlation coefficients were significantly correlated (Spearman's): ${ }^{*} P<0.05$, ${ }^{\star *} P<0.01$ 
and naringenin in $24 \mathrm{~h}$ urine $\left(r_{\mathrm{s}}=0.39\right)$ and naringenin in overnight urine $\left(r_{\mathrm{s}}=0.26\right)$. Likewise, $\beta$-cryptoxanthin also correlated with nearly all flavonoids and enterolactone, e.g. hesperetin in $24 \mathrm{~h}$ urine $\left(r_{\mathrm{s}}=0.34\right)$ and in overnight urine $\left(r_{\mathrm{s}}=0 \cdot 23\right)$, with the sum of all flavonoid aglycones and enterolactone in $24 \mathrm{~h}$ urine $\left(r_{\mathrm{s}}=0.33\right)$ and in overnight urine $\left(r_{\mathrm{s}}=0 \cdot 28\right)$. Furthermore, $\alpha$-carotene correlated with enterolactone in both $24 \mathrm{~h}$ urine $\left(r_{\mathrm{s}}=0.30\right)$ and overnight urine $\left(r_{\mathrm{s}}=0 \cdot 28\right)$, the sum of lutein, $\alpha$ - and $\beta$-carotene with enterolactone in $24 \mathrm{~h}$ urine $\left(r_{\mathrm{s}}=0.32\right)$ and overnight urine $\left(r_{\mathrm{s}}=0.32\right)$, and all carotenoids with the sum of all flavonoids and enterolactone in $24 \mathrm{~h}$ urine $\left(r_{\mathrm{s}}=0.31\right)$ and in overnight urine $\left(r_{\mathrm{s}}=0.31\right)$ (data not shown).

\section{The method of triads}

Triangular VC were first calculated for $24 \mathrm{~h}$ urinary flavonoid and enterolactone, FFQ intakes and plasma carotenoids, and then for overnight urine flavonoids and enterolactone, FFQ

Table 4. Validity coefficients (VC) and $95 \% \mathrm{Cl}$ for fruit and vegetable and tea intakes by the FFQ and the two independent biomarkers (BM), comparison of flavonoids determined in $24 \mathrm{~h}$ urine samples and overnight urine samples

(Validity coefficients and $95 \%$ confidence intervals, $n$ 191)

\begin{tabular}{|c|c|c|c|c|c|}
\hline & \multicolumn{2}{|c|}{$24 \mathrm{~h}$ urine } & & \multicolumn{2}{|c|}{ Overnight urine } \\
\hline & VC & $95 \% \mathrm{Cl}$ & & VC & $95 \% \mathrm{Cl}$ \\
\hline \multicolumn{6}{|c|}{ Citrus fruits and juices, BM1: citrus flavonoids, BM2: $\beta$-cryptoxanthin } \\
\hline $\mathrm{VC}_{\mathrm{BM} 1-\mathrm{T}^{*}}$ & 0.59 & $0.44,0.74$ & $\mathrm{VC}_{\mathrm{BM} 1-\mathrm{T}^{*}}$ & 0.39 & $0.22,0.56$ \\
\hline $\mathrm{VC}_{\mathrm{BM} 2-\mathrm{T}}$ & 0.66 & $0.51,0.82$ & $\mathrm{VC}_{\mathrm{BM} 2-\mathrm{T}}$ & 0.72 & $0.50,1.00$ \\
\hline $\mathrm{VC}_{\mathrm{FFQ}-\mathrm{T}}$ & 0.64 & $0.49,0.80$ & $\mathrm{VC}_{\mathrm{FFQ}-\mathrm{T}}$ & 0.59 & $0.38,0.83$ \\
\hline \multicolumn{6}{|c|}{ All fruit juices, BM1: citrus flavonoids, BM2: $\beta$-cryptoxanthin } \\
\hline $\mathrm{VC}_{\mathrm{BM} 1-\mathrm{T}^{*}}$ & 0.62 & $0.28,0.66$ & $\mathrm{VC}_{\mathrm{BM} 1-\mathrm{T}^{*}}$ & 0.46 & $0.25,0.63$ \\
\hline $\mathrm{VC}_{\mathrm{BM} 2-\mathrm{T}}$ & 0.63 & $0.48,1.00$ & $\mathrm{VC}_{\mathrm{BM} 2-\mathrm{T}}$ & 0.62 & $0.40,1.00$ \\
\hline $\mathrm{VC}_{\mathrm{FFQ}-\mathrm{T}}$ & 0.52 & $0.28,0.67$ & $\mathrm{VC}_{\mathrm{FFQ}-\mathrm{T}}$ & 0.53 & $0.28,0.75$ \\
\hline \multicolumn{6}{|c|}{ Legumes, BM1: enterolactone, BM2: lutein } \\
\hline $\mathrm{VC}_{\mathrm{BM} 1-\mathrm{T}^{*}}$ & 0.43 & $0.27,0.60$ & $\mathrm{VC}_{\mathrm{BM} 1-\mathrm{T}^{*}}$ & 0.40 & $0.24,0.57$ \\
\hline $\mathrm{VC}_{\mathrm{BM} 2-\mathrm{T}}$ & 0.73 & $0.52,1.00$ & $\mathrm{VC}_{\mathrm{BM} 2-\mathrm{T}}$ & 0.78 & $0.56,1.00$ \\
\hline $\mathrm{VC}_{\mathrm{FFQ}-\mathrm{T}}$ & 0.51 & $0.31,0.73$ & $\mathrm{VC}_{\mathrm{FFQ}-\mathrm{T}}$ & 0.48 & $0.30,0.71$ \\
\hline \multicolumn{6}{|c|}{ All vegetables and potatoes, BM1: enterolactone, BM2: all carotenoids } \\
\hline $\mathrm{VC}_{\mathrm{BM} 1-\mathrm{T}^{*}}$ & 0.53 & $0.33,0.82$ & $\mathrm{VC}_{\mathrm{BM} 1-\mathrm{T}^{*}}$ & 0.49 & $0.28,0.70$ \\
\hline $\mathrm{VC}_{\mathrm{BM} 2-\mathrm{T}}$ & 0.55 & $0.35,0.82$ & $\mathrm{VC}_{\mathrm{BM} 2-\mathrm{T}}$ & 0.64 & $0.40,1.00$ \\
\hline $\mathrm{VC}_{\mathrm{FFQ}-\mathrm{T}}$ & 0.49 & $0.27,0.72$ & $\mathrm{VC}_{\mathrm{FFQ}-\mathrm{T}}$ & 0.42 & $0.21,0.64$ \\
\hline \multicolumn{6}{|c|}{ All vegetables, not potatoes, BM1: enterolactone, BM2: all carotenoids } \\
\hline $\mathrm{VC}_{\mathrm{BM} 1-\mathrm{T}^{*}}$ & 0.49 & $0.32,0.66$ & $\mathrm{VC}_{\mathrm{BM} 1-\mathrm{T}^{*}}$ & 0.47 & $0.30,0.64$ \\
\hline $\mathrm{VC}_{\mathrm{BM} 2-\mathrm{T}}$ & 0.61 & $0.40,0.86$ & $\mathrm{VC}_{\mathrm{BM} 2-\mathrm{T}}$ & 0.66 & $0.43,0.94$ \\
\hline $\mathrm{VC}_{\mathrm{FFQ}-\mathrm{T}}$ & 0.57 & $0.37,0.80$ & $V_{C_{F F Q-T}}$ & 0.52 & $0.31,0.76$ \\
\hline \multicolumn{6}{|c|}{$\begin{array}{l}\text { All fruits, juices, vegetables and potatoes, BM1: flavonoids + } \\
\text { enterolactone, BM2: all carotenoids }\end{array}$} \\
\hline $\mathrm{VC}_{\mathrm{BM} 1-\mathrm{T}^{*}}$ & 0.58 & $0.39,0.82$ & $\mathrm{VC}_{\mathrm{BM} 1-\mathrm{T}^{*}}$ & 0.45 & 0.66 \\
\hline $\mathrm{VC}_{\mathrm{BM} 2-\mathrm{T}}$ & 0.53 & $0.34,0.72$ & $\mathrm{VC}_{\mathrm{BM} 2-\mathrm{T}}$ & 0.69 & $0.43,1.00$ \\
\hline $\mathrm{VC}_{\mathrm{FFQ}-\mathrm{T}}$ & 0.56 & $0.38,0.76$ & $V_{\mathrm{FFQ}-\mathrm{T}}$ & 0.43 & $0.22,0.64$ \\
\hline \multicolumn{6}{|c|}{$\begin{array}{l}\text { All fruits, juices and vegetables, not potatoes, BM1: flavonoids + } \\
\text { enterolactone, BM2: all carotenoids }\end{array}$} \\
\hline $\mathrm{VC}_{\mathrm{BM} 1-\mathrm{T}^{*}}$ & 0.50 & $0.28,0.77$ & $\mathrm{VC}_{\mathrm{BM} 1-\mathrm{T}^{*}}$ & 0.41 & $0.22,0.65$ \\
\hline & 0.61 & $0.37,0.98$ & $\mathrm{VC}_{\mathrm{BM} 2-\mathrm{T}}$ & 0.76 & $0.42,1.00$ \\
\hline $\mathrm{VC}_{\mathrm{FFQ}-\mathrm{T}}$ & 0.43 & $0.24,0.62$ & $V_{C_{F F Q-T}}$ & 0.35 & $0.17,0.55$ \\
\hline \multicolumn{6}{|c|}{ Tea, BM1: kaempferol, BM2: lutein $+\alpha$-carotene $+\beta$-carotene } \\
\hline $\mathrm{VC}_{\mathrm{BM} 1-\mathrm{T}^{*}}$ & 0.66 & $0.37,1.00$ & $\mathrm{VC}_{\mathrm{BM} 1-\mathrm{T}^{*}}$ & 0.44 & $0.16,1.00$ \\
\hline$V_{C_{B M 2-T}}$ & 0.29 & $0.14,0.47$ & $\mathrm{VC}_{\mathrm{BM} 2-\mathrm{T}}$ & 0.45 & $0.18,1.00$ \\
\hline$V_{\text {FFQ-T }}$ & 0.57 & $0.32,0.95$ & $V_{\text {FFQ-T }}$ & 0.37 & $0.14,0.67$ \\
\hline
\end{tabular}

* $\mathrm{VC}$ for comparison of the flavonoid biomarker in $24 \mathrm{~h} v$. overnight urine samples. intakes and plasma carotenoids (Table 4). For all food items, the $\mathrm{VC}$ for the flavonoid biomarker in $24 \mathrm{~h}$ urine $\left(\mathrm{VC}_{\mathrm{BM} 1-\mathrm{T}}\right)$ were higher (range 0.43-0.66) than for the flavonoid biomarker in overnight urine (range 0.39-0.49). The same was seen for the $\mathrm{FFQ}$ intake $\left(\mathrm{VC}_{\mathrm{FFQ}-\mathrm{T}}\right)$, where the $\mathrm{VC}$ for the $24 \mathrm{~h}$ urinary flavonoids and enterolactone (range 0.43-0.64) were higher than those for the overnight urine biomarker (range 0.35-0.59).

\section{Discussion}

The main assumption behind dietary biomarkers is that they are objective measures and are independent of all the biases and errors associated with study subjects and dietary assessment methods ${ }^{(3)}$. It is important that the biological sample collections are unannounced, or at least that the purpose of urine or blood sampling is unknown to the participants, as in the present study. Otherwise, biomarkers may be affected by some of the same biases as self-reported dietary assessment methods.

In spite of the quantitative differences between the amounts of flavonoids and enterolactone in $24 \mathrm{~h}$ urine and overnight urine, ranking of individuals by the two methods showed strong agreement. Significant Spearman's correlations between the intakes of fruits, vegetables, juices and tea reported by the Inter99 FFQ and the flavonoid biomarker in $24 \mathrm{~h}$ as well as in overnight urine indicated that the flavonoid biomarker in both $24 \mathrm{~h}$ and overnight urine can be used to rank individuals according to high or low intakes of fruits, vegetables, juices and tea in the Inter99 cohort (Table 3). The VC for the FFQ ranged from 0.43 to 0.64 using $24 \mathrm{~h}$ urine and from 0.35 to 0.59 using overnight urine, indicating that the intake of fruits, vegetables, juices and tea were reflected by flavonoids both in overnight urine and in $24 \mathrm{~h}$ urine. Together, this indicates a reasonably stable ranking of individuals in both $24 \mathrm{~h}$ and overnight urine, which is of major importance for large epidemiological studies that typically only obtain overnight urine or spot urine samples.

In the present study, the FFQ-estimated intake of fruits, vegetables, juices and tea overall showed better agreement with the carotenoid biomarkers than with the flavonoid biomarkers. The Inter99 FFQ is a retrospective method covering the previous month of intake. Urinary flavonoids and enterolactone are short-term dietary biomarkers and thus the estimated intakes of fruits, vegetables, juices and tea in the Inter99 cohort would be expected to have a stronger correlation with the carotenoid biomarker, since the carotenoid biomarker is covering a much longer time frame (weeks to months) than the flavonoids in $24 \mathrm{~h}$ and overnight urine. Few validation studies ${ }^{(9,14,16,17)}$ have previously included both flavonoids and carotenoids as biomarkers for fruit and vegetable intake. Carlsen et al. ${ }^{(17)}$ reported higher correlation coefficients for FFQ-estimated fruit, juice and vegetable intakes with total plasma carotenoids than with $24 \mathrm{~h}$ total flavonoids, while the opposite was seen in three other validation studies $^{(9,14,16)}$. This may indicate that different structures of self-reported dietary methods, differences in sample size and differences in the study population influence the results. 
In order to strengthen the performance of flavonoid biomarkers, collection of two or more overnight urine samples, rather that just one, could be a choice of strategy. The major reason why $24 \mathrm{~h}$ urine collection is considered to be difficult is the burden it imposes on participants, as they have to bring the collection bottles along through the whole day, e.g. to work or school. It is much easier to donate several overnight or spot urine samples than to complete one $24 \mathrm{~h} \mathrm{col-}$ lection. Furthermore, if the overnight urine collections were pooled before the chemical LC-MS analysis, the cost would be held on the approximately same level as if only one overnight urine sample was used. A pool of several overnight urine samples, for instance four collections evenly distributed over a whole year, furthermore could turn the flavonoid biomarker into a long-term dietary biomarker, also taking seasonality into consideration. This would increase the applicability and value of the flavonoid biomarker in future diet-disease investigations. The usefulness of urinary flavonoids and other polyphenolic compounds in overnight urine as biomarkers of fruit and vegetable intake is supported by the findings of Mennen et al. ${ }^{(20)}$. They measured thirteen polyphenols and metabolites (chlorogenic acid, caffeic acid, $m$-coumaric acid, gallic acid, 4-O-methylgallic acid, quercetin, isorhamnetin, kaempferol, hesperetin, naringenin, phloretin, enterolactone and enterodiol) in morning spot urine samples and found that the apple consumption was significantly correlated with phloretin, grapefruit consumption with naringenin, orange with hesperetin and citrus fruit consumption with both naringenin and hesperetin, with $r_{\mathrm{s}}$ coefficients ranging from 0.31 to 0.57 . The combination of fruits and/or fruit juices was furthermore positively correlated with gallic acid and 4-O-methylgallic acid, isorhamnetin, kaempferol, hesperetin, naringenin and phloretin $\left(r_{\mathrm{s}}=0 \cdot 24-0 \cdot 44\right)$, and they concluded that several polyphenols measured in a morning spot urine sample may be used as biomarkers of polyphenol-rich food intake ${ }^{(20)}$. In Mennen et al. ${ }^{(20)}$, the morning spot urine sample refers to urine taken in the morning of the third day of the study before breakfast and was thus part of the $24 \mathrm{~h}$ urine collection. The urinary recovery of enterolactone and isolariciresinol has in several studies been explained by the intake of vegetables ${ }^{(31-35)}$. In accordance with this, the inclusion of enterolactone in the flavonoid biomarker in general improved the performance of the biomarker (see Table 3 ). Furthermore, the $24 \mathrm{~h}$ urinary recovery of enterolactone significantly correlated with the recovery of enterolactone in overnight urine $\left(r_{\mathrm{s}}=0.89\right.$; see Table 2$)$, indicating that the urinary recovery of enterolactone in overnight urine may also be a good biomarker of vegetable intake. The elimination half-life of enterolactone is relatively slow $(6-8 \mathrm{~h})^{(36)}$ when compared with flavanones (approximately $2 \mathrm{~h})^{(36)}$, and this may be one of the reasons why an overnight urine sample may be sufficient to reflect the previous day's intake of vegetables. Furthermore, the urinary recovery of enterolactone is rather high $(14-37 \%)^{(37)}$ when compared with flavonols $(0 \cdot 1-6 \%)^{(36)}$, and this may increase the sensitivity of enterolactone as a biomarker of vegetable intake.

In the present study, we applied the method of triads to evaluate the performance of the flavonoid biomarker in overnight urine relative to $24 \mathrm{~h}$ urine. The $\mathrm{VC}$ were lower for one single overnight urine sample, but comparable with those obtained for $24 \mathrm{~h}$ urine (VC: $0.39-0.49$ and 0.43-0.66, respectively). There is no general agreement as to what is considered as an acceptable magnitude for correlation and VC in dietary validation studies.

Although the biomarkers are objective measures of dietary intakes and not hampered by recall and estimation errors, correlation coefficients between dietary estimates and the biomarkers are generally lower than correlations between the two dietary methods. This is because biomarker concentrations are influenced by individual differences in absorption, metabolism and distribution, which, again, are influenced by age, weight, smoking and other factors ${ }^{(2,38)}$. The VC obtained in the present study were of comparable magnitudes as reported in other studies using two biomarkers, and as in other studies using the triangular method, the CI were wide $^{(8,16,17)}$. A main finding in the present study was that the relative validity of the FFQ regarding fruit, vegetable, juice and tea intake was acceptable whether using $24 \mathrm{~h}$ urine or overnight urine.

The major strength of the present validation of the flavonoid biomarkers is the inclusion of two independent reference methods of fruit and vegetable intake, enabling correct use of the method of triads ${ }^{(38-42)}$. In two previous studies ${ }^{(16,17)}$, these biomarkers have been applied to validate FFQ for intakes of fruit and vegetable, and in both studies, $24 \mathrm{~h}$ urine collections were used for the flavonoid biomarker. In the study by Brantsæeter et al. ${ }^{(16)}$, the flavonoid biomarker produced the highest VC with respect to fruit intakes, whereas the carotenoid biomarker produced the highest $\mathrm{VC}$ with respect to vegetable intakes. Carlsen et al. ${ }^{(17)}$ used two $24 \mathrm{~h}$ urine collection as the basis for the flavonoid biomarker, but the VC for fruit and/or vegetable intakes were higher for the carotenoid biomarker than for the flavonoid biomarker. Similar to Carlsen et al., we found higher VC for the carotenoid biomarker than for the flavonoid biomarker independent of whether the flavonoid biomarker was measured in $24 \mathrm{~h}$ urine or overnight spot urine. The discrepancy between studies may most probably be explained by the differing level of details in the assessment of fruit and vegetables and by other differences in the populations being studied. More studies are needed to refine the flavonoid biomarker for use in overnight and spot urine samples so that biomarkers may be included not only in validation studies but also as independent markers of dietary intake.

\section{Conclusions}

The main strength of the present study is the inclusion of two independent reference methods of fruit and vegetable intake, enabling correct use of the triangular method for the evaluation of flavonoids in overnight urine as a biomarker of fruit, vegetable and beverage intake. The present study indicates that flavonoids and enterolactone excreted in an overnight urine sample provide a valid estimate of the fruit, vegetable, juice and tea intake in the Inter99 cohort. Collection of $24 \mathrm{~h}$ urine is difficult and time consuming, and therefore 
overnight urine may be a more convenient tool than $24 \mathrm{~h}$ urine for the assessment and validation of fruit, juice, vegetable and tea intakes in epidemiological studies.

\section{Acknowledgements}

The authors thank Anni Schou and Joan Elizabeth Frandsen from the Department of Toxicology and Risk Assessment for Expert Technical Assistance. This study was funded by the Research Centre for Environmental Health, Danish Ministry of the Interior and Health (ISMF) and the Danish Research Council (FELFO). The other authors declare that they have no competing interests. K. S. K. was involved in the preparation of the manuscript, contributed to the analyses of urine flavonoids and the statistical analyses. A. L. B. conducted the statistical analyses and contributed to the data interpretation and the manuscript. S. E. R. performed the analyses of urine flavonoids and contributed to the manuscript. L. K. and U. T. carried out the design of the validation study, collected and analysed the FFQ data and contributed to the manuscript. A. B. carried out the analyses of plasma carotenoids and contributed to the manuscript. J. J. performed the para-aminobenzoic acid analysis and contributed to the manuscript. All authors read and approved the final manuscript.

\section{References}

1. Subar AF, Thompson FE, Kipnis V, et al. (2001) Comparative validation of the Block, Willett, and National Cancer Institute food frequency questionnaires: the Eating at America's Table Study. Am J Epidemiol 154, 1089-1099.

2. Willett WC (1998) Nutritional Epidemiology, 2nd ed. Oxford: Oxford Medical Publications.

3. Jenab M, Slimani N, Bictash M, et al. (2009) Biomarkers in nutritional epidemiology: applications, needs and new horizons. Hum Genet 125, 507-525.

4. Byers T, Trieber F, Gunter E, et al. (1993) The accuracy of parental reports of their children's intake of fruits and vegetables: validation of a food frequency questionnaire with serum levels of carotenoids and vitamins $\mathrm{C}, \mathrm{A}$, and $\mathrm{E}$. Epidemiology 4, 350-355.

5. Resnicow K, Odom E, Wang T, et al. (2000) Validation of three food frequency questionnaires and 24-hour recalls with serum carotenoid levels in a sample of AfricanAmerican adults. Am J Epidemiol 152, 1072-1080.

6. Kristal AR, Vizenor NC, Patterson RE, et al. (2000) Precision and bias of food frequency-based measures of fruit and vegetable intakes. Cancer Epidemiol Biomarkers Prev 9 , 939-944.

7. Bogers RP, Van Assema P, Kester AD, et al. (2004) Reproducibility, validity, and responsiveness to change of a short questionnaire for measuring fruit and vegetable intake. $\mathrm{Am}$ J Epidemiol 159, 900-909.

8. Andersen LF, Veierød MB, Johansson L, et al. (2005) Evaluation of three dietary assessment methods and serum biomarkers as measures of fruit and vegetable intake, using the method of triads. Br J Nutr 93, 519-527.

9. Mikkelsen TB, Olsen SF, Rasmussen SE, et al. (2007) Relative validity of fruit and vegetable intake estimated by the food frequency questionnaire used in the Danish National Birth Cohort. Scand J Public Health 35, 172-179.
10. Toft U, Kristoffersen L, Ladelund S, et al. (2008) Relative validity of a food frequency questionnaire used in the Inter99 study. Eur J Clin Nutr 62, 1038-1046.

11. Burrows TL, Warren JM, Colyvas K, et al. (2008) Validation of overweight children's fruit and vegetable intake using plasma carotenoids. Obesity 17, 162-168.

12. Slater B, Enes CC, López RV, et al. (2010) Validation of a food frequency questionnaire to assess the consumption of carotenoids, fruits and vegetables among adolescents: the method of triads. Cad Saude Publica 26, 2090-2100.

13. Crispim SP, Geelen A, Souverein OW, et al. (2011) Biomarker-based evaluation of two 24-h recalls for comparing usual fish, fruit and vegetable intakes across European centers in the EFCOVAL Study. Eur J Clin Nutr 65, S38-S47.

14. Nielsen SE, Freese R, Kleemola P, et al. (2002) Flavonoids in human urine as biomarkers for intake of fruits and vegetables. Cancer Epidemiol Biomarkers Prev 11, 459-466.

15. Krogholm KS, Bredsdorff L, Alinia S, et al. (2010) Free fruit at workplace increases total fruit intake: a validation study using $24 \mathrm{~h}$ dietary recall and urinary flavonoid excretion. Eur J Clin Nutr 64, 1222-1228.

16. Brantsæter AL, Haugen M, Rasmussen SE, et al. (2007) Urine flavonoids and plasma carotenoids in the validation of fruit, vegetable, and tea intake during pregnancy in the Norwegian Mother and Child Cohort Study (MoBa). Public Health Nutr 10, 838-847.

17. Carlsen MH, Karlsen A, Lillegaard ITL, et al. (2011) Relative validity of fruit and vegetable intake estimated from an FFQ, using carotenoid and flavonoid biomarkers and the method of triads. Br J Nutr 105, 1530-1538.

18. Krogholm KS, Haraldsdottir J, Knuthsen P, et al. (2004) Urinary total flavonoid excretion but not 4-pyridoxic Acid or potassium can be used as a biomarker for the intake of fruits and vegetables. J Nutr 134, 445-551.

19. Mennen LI, Sapinho D, Ito H, et al. (2006) Urinary flavonoids and phenolic acids as biomarkers of intake for polyphenolsrich foods. Br J Nutr 96, 191-198.

20. Mennen LI, Sapinho D, Ito H, et al. (2008) Urinary excretion of 13 dietary flavonoids and phenolic acids in free-living healthy subjects - variability and possible use as biomarkers of polyphenol intake. Eur J Clin Nutr 62, 519-525.

21. World Health Organization (1999) Definition, Diagnosis and Classification of Diabetes Mellitus and its Complications. Report of a WHO Consulation. WHO/NCD/NCS/99-2. Geneva: WHO.

22. Jorgensen T, Borch-Johnsen K, Thomsen TF, et al. (2003) A randomized non-pharmacological intervention study for prevention of ischaemic heart disease: baseline results Inter99. J Cardiovasc Risk 10, 377-386.

23. Saxholt E, Møller A \& Ygil K (2005) Danish Food Composition Databank version 6.0 [Fødevaredatabanken version 6.0]. Søborg: Department of Nutrition, The Danish Institute for Food and Veterinary Research. http://www.foodcomp.dk

24. Lauritsen J (1998) FoodCalc 1.3 1998. http://www.http:/foodcalc.dk

25. Jakobsen J, Ovesen L, Fagt S, et al. (1997) Para-aminobenzoic acid used as a marker for completeness of $24 \mathrm{~h}$ urine: assessment of control limits for specific HPLC method. Eur J Clin Nutr 51, 514-519.

26. Nielsen SE, Freese R, Cornett C, et al. (2000) Identification and quantification of flavonoids in human urine samples by column-switching liquid chromatography coupled to atmospheric pressure chemical ionization mass spectrometry. Anal Chem 72, 1503-1509.

27. Nielsen IL, Haren GR, Magnussen EL, et al. (2003) Quantification of anthocyanins in commercial black currant juices by simple high-performance liquid chromatography. 
Investigation of their $\mathrm{pH}$ stability and antioxidative potency. J Agri Food Chem 51, 5861-5866.

28. Kaaks RJ (1997) Biochemical markers as additional measurements in studies of the accuracy of dietary questionnaire measurements: conceptual issues. Am J Clin Nutr 65, 1232S-1239S

29. Ocke MC \& Kaaks RJ (1997) Biochemical markers as additional measurements in dietary validity studies: application of the method of triads with examples from the European Prospective. Am J Clin Nutr 65, 1240S-1245S.

30. R Development Core Team (2005) R: A Language and Environment for Statistical Computing. Vienna: R Foundation for Statistical Computing. http://www.r-project.org/.

31. Kilkkinen A, Stumpf K, Pietinen P, et al. (2001) Determinants of serum enterolactone concentration. Am J Clin Nutr 73, 1094-1100.

32. Horner NK, Kristal AR, Prunty J, et al. (2002) Dietary determinants of plasma enterolactone. Cancer Epidemiol Biomarkers Prev 11, 121-126.

33. Johnsen NF, Hausner H, Olsen A, et al. (2004) Intake of whole grains and vegetables determines the plasma enterolactone concentration of Danish women. J Nutr 134, 2691-2697.

34. Milder IEJ, Feskens EJM, Arts ICW, et al. (2005) Intake of the plant lignans secoisolariciresinol, matairesinol, lariciresinol and pinoresinol in Dutch men and women. $J$ Nutr 135, 1202-1207.

35. Touillaud MS, Thiébaut AC, Fournier A, et al. (2007) Dietary lignan intake and postmenopausal breast cancer risk by estrogen and progesterone receptor status. J Natl Cancer Inst 99, 475-486.

36. Manach C, Williamson G, Morand C, et al. (2005) Bioavailability and bioefficacy of polyphenols in humans. I. Review of 97 bioavailability studies. Am J Clin Nutr 81, 230S-242S.

37. Pérez-Jiménez J, Hubert J, Hooper L, et al. (2010) Urinary metabolites as biomarkers of polyphenol intake in humans: a systematic review. Am J Clin Nutr 92, 801-809.

38. van Kapple AL, Steghens J-P, Zeleniuch-Jacquotte A, et al. (2001) Serum carotenoids as biomarkers of fruit and vegetable consumption. Public Health Nutr 4, 829-835.

39. Kabagambe EK, Baylin A, Allan DA, et al. (2001) Application of the method of triads to evaluate the performance of food frequency questionnaires and biomarkers as indicators of long-term dietary intake. Am J Epidemiol 154, 1126-1135.

40. Brevik A, Veierød MB, Drevon CA, et al. (2005) Evaluation of the odd fatty acids 15:0 and 17:0 in serum and adipose tissue as markers of intake of milk and dairy fat. Eur J Clin Nutr 59, 1417-1422.

41. McNaughton SA, Marks GC, Gaffney P, et al. (2005) Validation of a food-frequency questionnaire assessment of carotenoid and vitamin $\mathrm{E}$ intake using weighed food records and plasma biomarkers: the method of triads model. Eur J Clin Nutr 59, 211-218.

42. McNaughton SA, Hughes MC \& Marks GC (2007) Validation of a FFQ to estimate the intake of PUFA using plasma phospholipid fatty acids and weighed foods records. BrJ Nutr $\mathbf{9 7}$, 561-568. 